\title{
Normal Acoustic Reflex Amplitude Growth and the Influence of Cochlear Hearing Loss
}

\author{
Juliette Womersley B.Sc(Log) (Cape Town) \\ Lucille Dickens B(Log) (Pretoria) \\ Department of Logopaedics, \\ University of Cape Town
}

\begin{abstract}
,
The nature of acoustic reflex amplitude (ARA) growth at $1 \mathrm{KHz}$ and $2 \mathrm{KHz}$ was investigated in normal hearing and cochlear disordered subjects subdivided into Meniere's Disease and heterogeneous pathology groups. Statistical and graphical analyses revealed significant inter-group variation in ARA growth rate. The normal and Meniere's groups behaved similarly, while the heterogeneous group demonstrated a faster ARA growth rate. The differential sensitivity of various measurement methods was examined. Explanations were put forward to account for variability in ARA data amongst cochlear disordered subjects. It was concluded that the clinical sensitivity of ARA measurement was questionable.
\end{abstract}

\section{OPSOMMING}

Die toename van die akoestiese refleks amplitude (ARA) by $1 \mathrm{KHz}$ en $2 \mathrm{KHz}$ is in normaalhorendes en proefpersone met kogliêre letsels ondersoek. Laasgenoemde is in Ménière se siekte en groepe met 'n heterogene patologie onderverdeel. 'n Betekenisvolle variasie tussen groepe m.b.t. die ARA-groeitempo is d.m.v. statistiese en grafiese analises bevind. Ooreenkomste tussen die normale en die Ménière se groepe is aangetref terwyl daar ' $n$ toename in die ARA-groeitempo van die heterogene groep was. Verder is die sensitiwiteitsverskil van verskeie metingsmetodes ondersoek. Ten einde die veranderlikheid in ARA-data tussen proefpersone met kogliêre letsels te verantwoord, is verskeie verklarings gebied. Die gevolgtrekking is gemaak dat die kliniese sensitiwiteit van die ARA-meting bevraagteken is.

The role of acoustic reflex measurement in determining the nature of sensori-neural hearing loss has been well established. Traditionally the acoustic reflex threshold test, a static measure, and the reflex decay test, a dynamic temporal measure, are employed for this purpose (Jerger, 1975). Measurement of other dynamic properties such as amplitude and latency has not yet achieved the same clinical status. Borg (1976) however, stated that such properties may contribute significantly to clinical diagnosis in impedance audiometry if they are proven to be pathology sensitive.

Acoustic reflex amplitude (ARA) is defined as the change in acoustic impedance between quiescent and reflexive states. ARA is intensity dependent: for pure tone stimulation it has a dynamic range of 20-30 dB, representing the intensity range over which the reflex shows an amplitude growth (Wilson and McBride, 1978). The nature of ARA growth in normal subjects has been variably reported in the literature. Uliel (1980) and Clemis and Sarno (1980) reported a linear function while several other investigators have reported a curvilinear function (Dallos, 1964; Sprague, Wiley and Block, 1981; Wilson and McBride, 1978). Inter-study variability in the description of normal ARA growth could have resulted from a nonstandardised basis of amplitude measurement; sensation level (SL) versus hearing level (HL) measurement methods. Sprague et al. (1981) employed both SL and HL in their data analysis and demonstrated an ARA configuration difference accordingly.

- This lack of agreement between researchers is also evident in the literature on ARA in the cochlear hearing loss population. Uliel (1980) investigated an ascending-descending ARA function in normal and cochlear disordered subjects, by HL measurement. The growth pattern characteristic of cochlear disordered subjects without concomitant loudness recruitment was similar to that of the normal group. In contrast, cochlear disordered subjects with concomjtant loudness recruitment demonstrated a faster than normal amplitude growth. An increased growth rate was also repeatedly observed by Clemis and Sarno (1980) in Meniere's Disease subjects, at $\mathrm{IKHz}$ and $2 \mathrm{KHz}$.

In contrast with these findings, Petersen and Liden (1972) and Beedle and Harford (1973) reported a slower growth rate in pathological ears of variable cochlear etiology, than in normal ears. Both Uliel (1980) and Beedle and Harford (1973) specifically investigated ears with loudness recruitment and thus the discrepancy in their respective findings is particularly notable. A further confusion is that Jerger and Hayes (1983) reported an abnormally slow growth rate to be characteristic of a retrocochlear group. These discrepancies indicate that the influence of cochlear pathology on AR'A has not been unequivocally established. Furthermore, since Uliel (1980) did not find an abnormal growth rate to be characteristic of all cochlear disordered subjects, it is logical to suspect that the influence of cochlear disorder on ARA might vary as a function of pathology. The need for further research on ARA in the cochlear population is clear. However, results cannot be classified validly as "faster" or "slower" than normal, until "normal" growth has been unequivocally defined. Further investigation in to the shape of the ARA growth function in normal subjects is therefore also necessary.

\section{METHODOLOGY}

AIMS

The amplitude growth of the acoustic reflex was investigated at $\mathrm{IKHz}$ and $2 \mathrm{KHz}$, in normal hearing and cochlear disordered subjects with the aim of

1. describing the configuration of the ARA growth function in normal hearing subjects for various measurement methods, namely: HL, SL, $\Delta \mathrm{HL}$, and $\Delta \mathrm{SL}$;

The South African Journal of Communication Disorders, Vol. 32, 1985 
2. investigating the influence of cochlear dysfunction on the ARA growth function. Specifically, to investigate ARA in a group of Meniere's Disease subjects, and a group of subjects with variable cochlear etiology, excluding Meniere's Disease;

3. examining the variable sensitivity of different measurement methods in distinguishing between the normal and pathological subject groups.

\section{SUBJECTS}

The subject sample in this investigation comprised three groups: a control group (A) of 16 normal hearing subjects (mean age 24 years; 38 test ears), an experimental group (B) of six subjects with Meniere's Disease (mean age 38 years; six test ears), and a further experimental group (C) of four subjects with variable cochlear etiology, excluding Meniere's Disease, (mean age 40 years, six test ears). This age limit of 20-50 years was imposed since ARA data has been shown to be relatively stable across this age range (Osterhammel and Osterhammel, 1979). Both sexes were represented.

Subjects were selected on the basis of case-history findings and audiologic results obtained by the author from a battery comprising pure tone air and bone conduction audiometry, impedance audiometry, the Metz Recruitment and Rosenburg Tone Decay tests. Table 1 summarises the specific criteria according to which subjects were differentiated into groups $\mathrm{A}, \mathrm{B}$ and $\mathrm{C}$.

\section{EQUIPMENT}

A Madsen Electro-Acoustic Impedance Audiometer (model Z073A) which delivered a $220 \mathrm{~Hz}$ probe tone was used. This was calibrated according to standards set out in IEC publication 318. A Hewlett Packard Moseley X-Y Plotter (model 7035A) was connected to the impedance meter. The $\mathrm{X}$-axis was activated by depression of the pure tone stimulus interrupter switch on the impedance meter, resulting in a time-locked 2 second excursion. Presentation of the 250 msec stimulus followed automatically but not immediately, allowing a baseline to be plotted before reflex elicitation.

The impedance meter was set at sensitivity 2 and the range of the $\mathrm{Y}$-axis was calibrated such that $0.05 \mathrm{cc}=0.04 \mathrm{mv}=1 \mathrm{~mm}$ on the chart paper. An acoustic reflex was recorded as a relative deflection from the baseline, representing an increase in input impedance (refer to Figure 1).

\section{EXPERIMENTAL PROCEDURE}

Tympanometry was performed on each test ear prior to experimental testing in order to determine the point of maximum compliance. The acoustic reflex testing was conducted by the contralateral stimulus mode at $1 \mathrm{KHz}$ and $2 \mathrm{KHz}$. The starting point for stimulus intensity was subject specific: testing began at reflex threshold and

\section{Table 1 Summary of specific criteria for subject selection and grouping}

\begin{tabular}{|c|c|c|c|}
\hline & GROUP A & GROUP B & GROUP C \\
\hline Detailed case-history & $\begin{array}{l}\text { Negative history of hearing } \\
\text { difficulty, ear pathology, } \\
\text { otologic surgery, noise } \\
\text { exposure and ototoxic drug } \\
\text { intake. }\end{array}$ & $\begin{array}{l}\text { Positive history of cochlear } \\
\text { sensori neural hearing loss, } \\
\text { negative history of middle ear } \\
\text { pathology and surgery, noise } \\
\text { exposure, acoustic trauma, } \\
\text { and ototoxic drug intake. } \\
\text { Positive history of Meniere's } \\
\text { Disease and associated } \\
\text { symptomatology, confirmed } \\
\text { by an E.N.T. specialist. }\end{array}$ & $\begin{array}{l}\text { Positive history of cochlear } \\
\text { sensori-neural hearing loss, } \\
\text { negative history of middle } \\
\text { ear pathology and otologic } \\
\text { surgery and meniere's Disease. }\end{array}$ \\
\hline Hearing thresholds & $\begin{array}{l}\text { No poorer than } 25 \mathrm{~dB} \text {. No } \\
\text { air-bone gap. }\end{array}$ & $\begin{array}{l}\text { Between } 25-75 \mathrm{~dB} \text { at speech } \\
\text { frequencies. No air-bone gap. }\end{array}$ & $\begin{array}{l}\text { Between } 25-75 \mathrm{~dB} \text { at speech } \\
\text { frequencies. No air-bone gap. }\end{array}$ \\
\hline Tympanometry & $\begin{array}{l}\text { Type-A } \\
\text { tympanogram } \\
\text { to rule out the } \\
\text { presence of middle ear } \\
\text { disórders. }\end{array}$ & $\begin{array}{l}\text { Type-A } \\
\text { tympanogram } \\
\text { to rule out the } \\
\text { presence of middle ear } \\
\text { disorders. }\end{array}$ & $\begin{array}{l}\text { Type-A } \\
\text { tympanogram } \\
\text { to rule out the } \\
\text { presence of middle ear } \\
\text { disorders. }\end{array}$ \\
\hline Static Compliance & $0.55 \mathrm{cc}-1.5 \mathrm{cc}$ & $0.5 \mathrm{cc}-1.55 \mathrm{cc}$ & $0.5 \mathrm{cc}-1.5 \mathrm{cc}$ \\
\hline Reflex Thresholds & $\begin{array}{l}\text { Between } 70-100 \\
\mathrm{~dB} \text { at all frequencies. }\end{array}$ & $\begin{array}{l}\text { Between } 70-100 \\
\mathrm{~dB} \text { at } 1 \mathrm{KHz} \text { and } 2 \mathrm{KHz} \text {, } \\
\text { contralaterally. }\end{array}$ & $\begin{array}{l}\text { Between } 70-100 \\
\mathrm{~dB} \text { at } 1 \mathrm{KHz} \text { and } 2 \mathrm{KHz} \text {, } \\
\text { contralaterally. }\end{array}$ \\
\hline $\begin{array}{l}\text { Supra-threshold } \\
\text { dynamic range }\end{array}$ & $\begin{array}{l}\text { Minimum of } 25 \\
\text { dBHL to allow for sufficient } \\
\text { ARA growth. }\end{array}$ & $\begin{array}{l}\text { Minimum of } 25 \\
\text { dBHL to allow for sufficient } \\
\text { ARA growth. }\end{array}$ & $\begin{array}{l}\text { Minimum of } 25 \\
\text { dBHL to allow for sufficient } \\
\text { ARA growth. }\end{array}$ \\
\hline Metz Test & Negative. & Positive: ARSL $<60 \mathrm{~dB}$ & ARSL $<60 \mathrm{~dB}$ \\
\hline Tone Decay Test & - & Negative. & Negative. \\
\hline
\end{tabular}




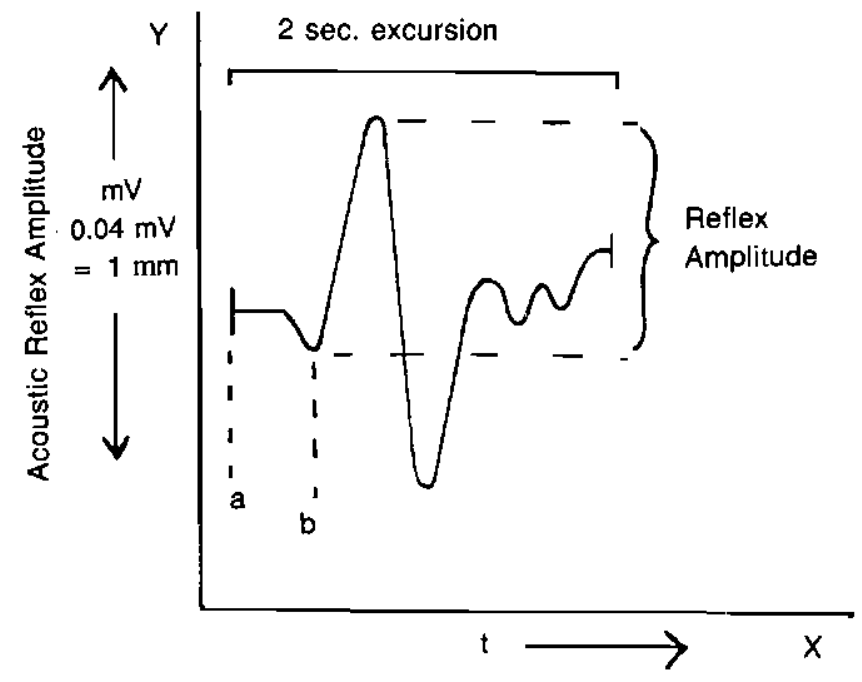

Figure 1 A sample reflex response at $95 \mathrm{dBHL}$, illustrating the configuration of reflex amplitude. $\mathrm{a}=$ interrupter switch depression: the distance between $a$ and $b$ represents the baseline before reflex elecitation.

proceeded in $5 \mathrm{~dB}$ increments up to $125 \mathrm{dBHL}$. In this manner a series of graphical figures (refer to Figure 1) were obtained representing reflex amplitude at consecutive stimulus levels, for each test ear at both frequencies.

\section{ANALYSIS OF RESULTS}

The graphical figures represented the raw data. The amplitude of each reflex was established by calculating the millimetre measurement from the lowest point of the positive deflection to the highest point representing the maximal increase in input impedance. Millimetre measurements were converted to $\mathrm{mV}$ 's according to the scale $-1 \mathrm{~mm}=0.04 \mathrm{mV} . \mathrm{mV}$ scores used in data analysis were restricted to those at hearing levels (HL) and sensation levels (SL) at which a reflex response was common to all test ears. Data were also tabulated separately for those normal subjects who demonstrated the broadest dynamic range of amplitude growth, thus forming a subgroup of the normal sample.

The following analyses were performed:

1. GRAPHICAL ANALYSIS

Mean ARA functions for the three subject groups were graphically displayed with the aim of examining the influence of subject group and measurement method variables on the configuration of these functions. Data for the subgroup of normal subjects was graphically displayed so as to examine the effect of dynamic range on function configuration.

2. SLOPE INDEX MEASUREMENT

Slope index values were calculated for each graphical figure, based either on the whole HL or SL stimulus range (100-125 dBHL or 0-25 dBSL) or based only on the final two HL or SL increments (120-125 dBHL or 20-25 dBSL); thus observed differences in overall or 'tail-end' function configurations could be quantified.

3. STATISTICAL ANALYSIS

The two-way analysis of variance statistic, with repeated measures on B (2-ANOVA-RB), was used to establish whether a significant interaction existed between subject group (variable A) and stimulus level (variable B). The simple main effects (SME) and Tukey's honestly significant difference (HSD) statistics were used to quantify further the variation in ARA between subject groups at specific stimulus levels.
All $\mathrm{HL}$ and SL data at $1 \mathrm{KHz}$ and $2 \mathrm{KHz}$ were converted to $\Delta \mathrm{HL}$ and $\Delta \mathrm{SL}$ data, by computing the $\mathrm{mV}$ difference between scores at consecutive stimulus levels. This data was analysed graphically with the aim of examining the influence of $\Delta \mathrm{HL}$ and $\Delta$ SL measurement methods on inter-group trends.

\section{RESULTS AND DISCUSSION}

\section{NORMALS}

The graphical representation of data from 38 test ears at $1 \mathrm{KHz}$ and $2 \mathrm{KHz}$, over a 100-125 dBHL range and a 0-25 dBSL range, revealed that the nature of ARA growth was neither mathematically linear or curvilinear (refer to Figure 2). This finding contrasts with the relevant literature which has variably reported ARA configurations in normal subject groups to be exactly linear (Uliel, 1980; Clemis and Sarno, 1980) or curvilinear (Dallos, 1964; Sprague et al., 1981; Wilson and McBride, 1978). It is possible that this discrepancy between present and other research findings is a function of the small sample size and considerable variability in function configurations, that characterised this study.

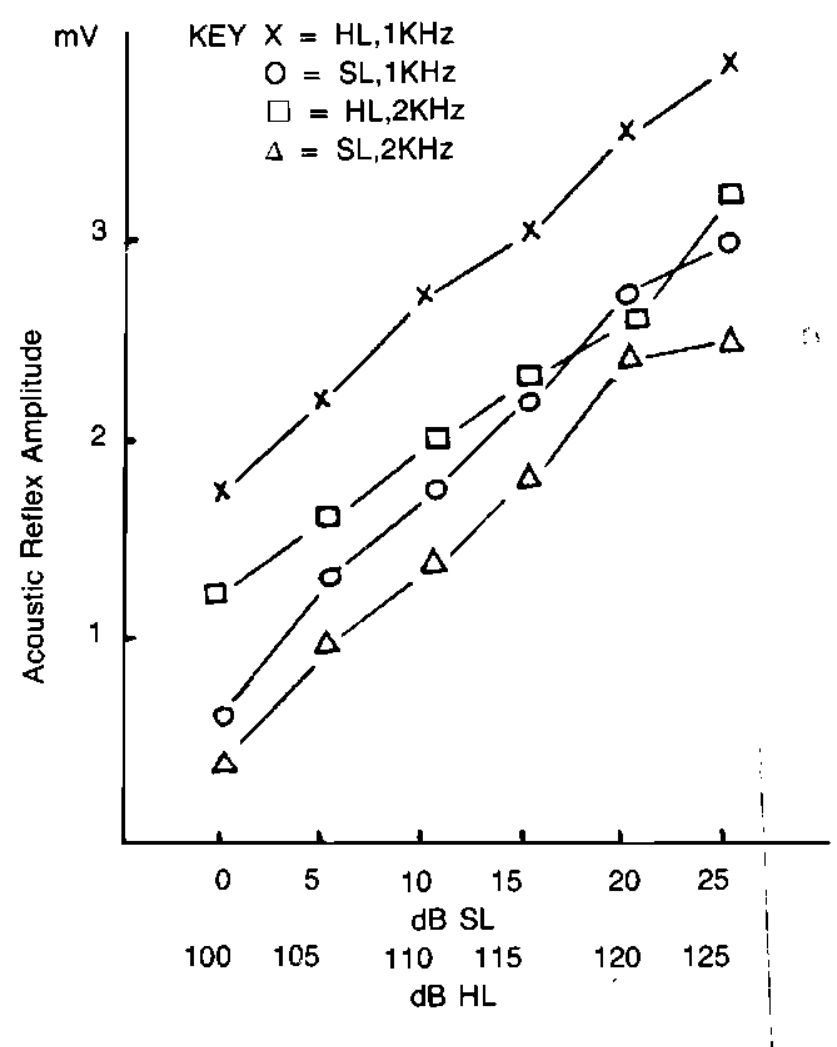

Figure 2 ARA functions for normal subjects at $1 \mathrm{KHz}$ and 2KHz for HL and SL data

The differential effect of measurement method on ARA configuration was visually evident at $2 \mathrm{KHz}$ but not at $1 \mathrm{KHz}$ (refer Figure 2). There was no difference between the HL-SL configurations at $1 \mathrm{KHz}$, whereas at $2 \mathrm{KHz}$ an asymptotic function was characteristic of the SL but not the HL function.

The obtained 'tail-end' slope index values were as follows:

$$
\begin{array}{lllrl}
\mathrm{HL} & 0.3 \mathrm{mV} & (1 \mathrm{KHz}) & \mathrm{SL} & 0.3 \mathrm{mv} \\
\mathrm{HL} & 0.5 \mathrm{mV} & (2 \mathrm{KHz}) & \mathrm{SL} & 0.1 \mathrm{mv}
\end{array}
$$

These values substantiated the graphical findings: while there was no difference between the $\mathrm{HL}$ and SL values at $\mathrm{IKHz}$, the SL index 


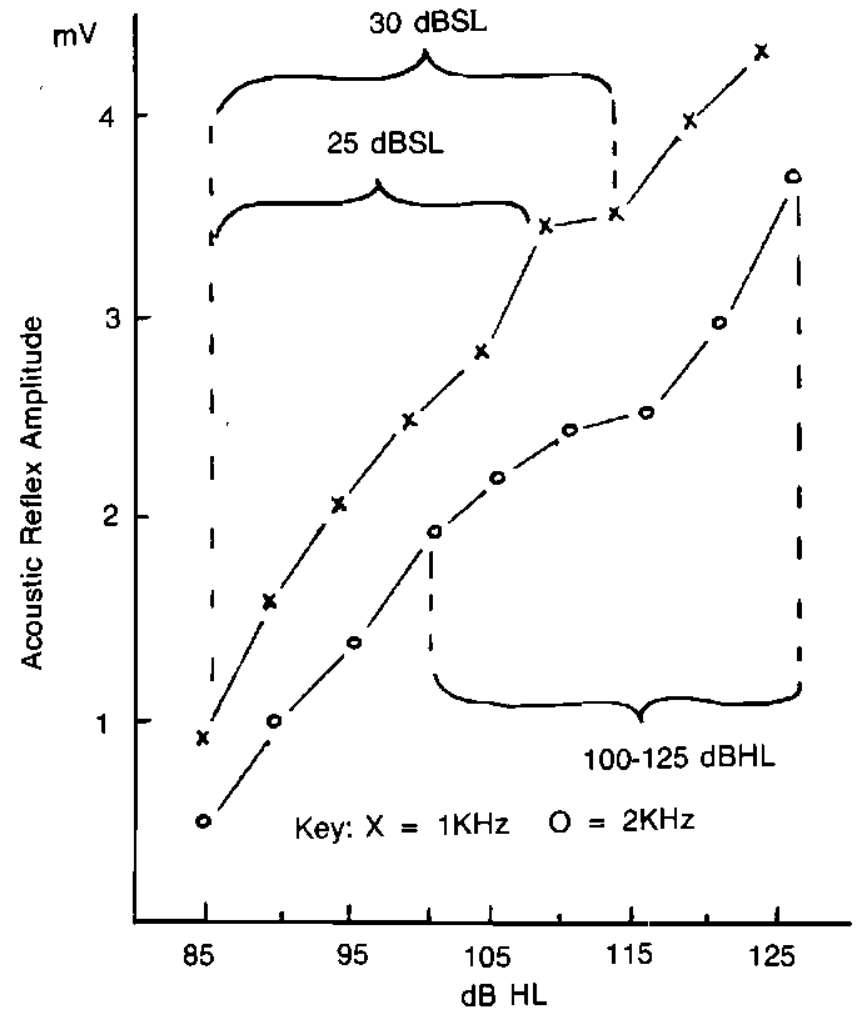

Figure 3 A complete ARA function for a sample of 10 normal subjects, with super imposed HL and SL ranges, at $1 \mathrm{KHz}$ and $2 \mathrm{KHz}$

at $2 \mathrm{KHz}$ was reduced relative to the $\mathrm{HL}$ value, indicating an asymptotic function

This HL-SL configuration difference is in keeping with the findings of Sprague et al (1981), and requires an explanation particularly in view of it's frequency selectively in this study. Figure 3 illustrates an ARA function for the subgroup of normal subjects who demonstrated a broad dynamic range (85-125 $\mathrm{dBHL}$ ) at $1 \mathrm{KHz}$ and $2 \mathrm{KHz}$. The superimposition of $\mathrm{HL}$ and SL ranges on the graphical figures reveals that the differences 'in function configuration description (such as asymptotic versus non-asymptotic) can result from analyses of different portions of a wide intensity range. This possibly explains discrepancy in descriptions reported in the literature: linear versus curvilinear. Figure 3 illustrates further that the absence of an asymptotic SL function at $1 \mathrm{KHz}$ was simply a function of the breadth of dynamic range under investigation, namely $25 \mathrm{dBSL}$; an asymptotic function would have resulted had a $30 \mathrm{dBSL}$ range been investigated. Considerable variability was found in the rate and pattern of ARA growth amongst normal subjects. This inter-subject variability was pronounced for HL measurement and relatively reduced for SL measurement, in keeping with the findings of Petersen and Linden (1972). A broad range of normal variability might obscure the clinical identification of mild or even moderate pathological deviance, and therefore it is implied that SL measurement offers a better prognosis for clinical sensitivity in ARA testing, than HL measurement, by reducing this range.

\section{INTER-GROUP COMPARISONS}

Graphical representation of the function configurations for groups $\mathrm{A}, \mathrm{B}$, and $\mathrm{C}$, for $\mathrm{SL}$ data at $\mathrm{KHz}$ and $2 \mathrm{KHz}$ revealed a marked trend; group $\mathrm{C}$ demonstrated a visually steeper ARA function (faster ARA growth rate), while groups A and B were similar regardless of stimulus parameters (refer to Figures 4 and 5). This trend was also characteristic of $\mathrm{HL}$ data at 1 and $2 \mathrm{KHz}$, although less pronounced.
Whole slope index values quantified and confirmed these findings: the highest values were consistently obtained for group $C$, indicating a faster ARA growth rate in this group than in either groups A or B (refer to Table 2).

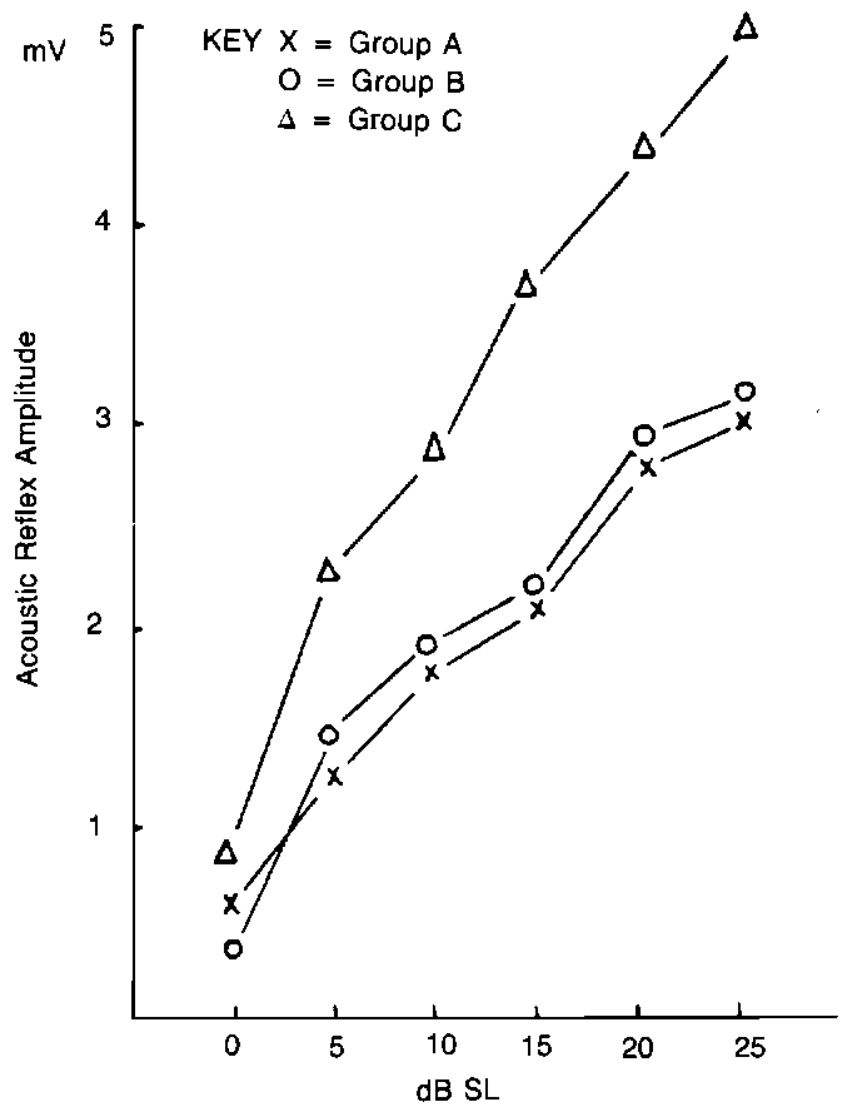

Figure 4 ARA functions at $1 \mathrm{KHz}$, for SL data, showing inter-group growth rate trends

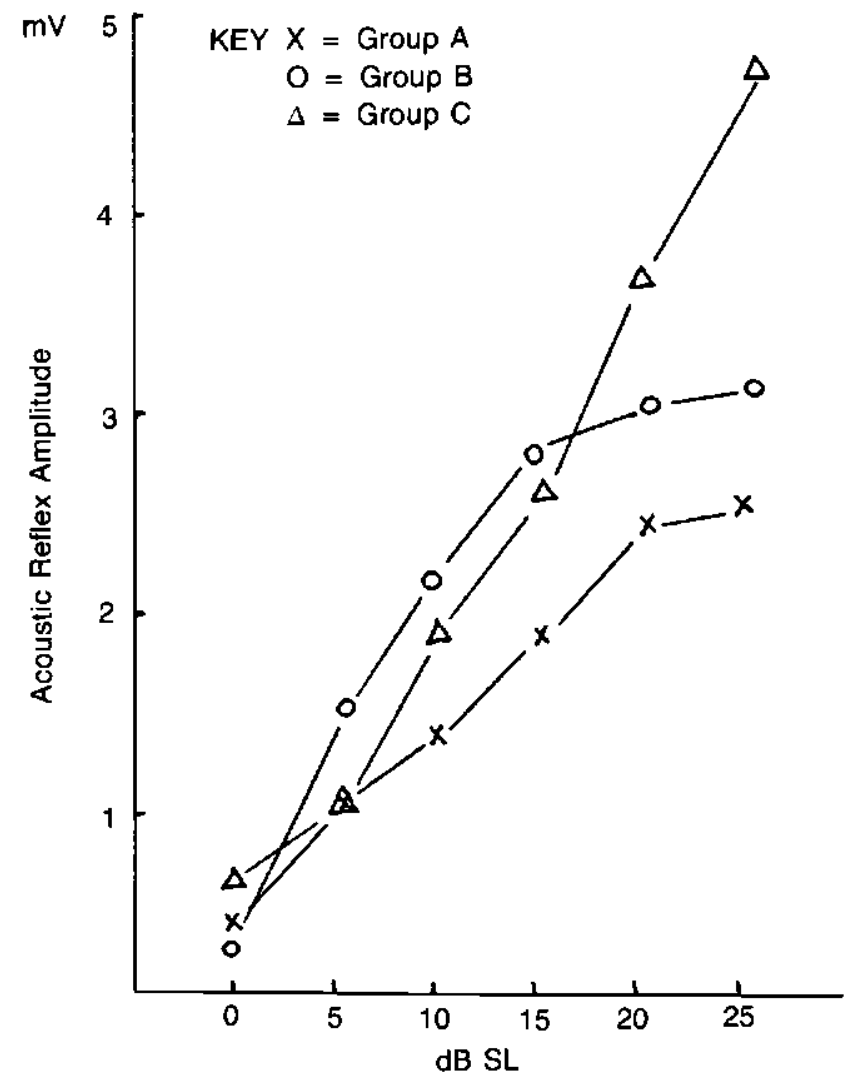

Figure 5 ARA functions at $2 \mathrm{KHz}$, for SL data, showing inter-group growth rate trends 
Tahle 2 Whole-slope index $\mathrm{mV}$ values for groups $\mathrm{A}$, $B$ and $C$

\begin{tabular}{|c|c|c|}
\hline GROUP & $\mathrm{HL}, \mathrm{I} \mathrm{KHz}$ & $\mathrm{SL}, 1 \mathrm{KHz}$ \\
\hline A & 0,4 & 0,4 \\
\hline B & 0,3 & 0,5 \\
\hline \multirow[t]{2}{*}{ C } & 0,6 . & 0,8 \\
\hline & HL., $2 \mathrm{KHz}$ & $\mathrm{SL}, 2 \mathrm{KHz}$ \\
\hline A & 0,3 & 0,4 \\
\hline B & 0.3 & 0,5 \\
\hline c & 0,8 & 0,8 \\
\hline
\end{tabular}

The 2-ANOVA-RB statistic for $\mathrm{HL}$ and SL measurement at $1 \mathrm{KHz}$ and $2 \mathrm{KHz}$, yielded significant $F$-ratio values $(\mathrm{p}<0.01$, and $\mathrm{p}<0.05$ for SL data at $2 \mathrm{KHz}$ ). The SME statistic indicated that significant variation within all subjects (variable A collapsed), existed at specific stimulus levels for $1 \mathrm{KHz}$ and $2 \mathrm{KHz}$, these levels being more numerous for SL than $\mathrm{HL}$ data, and for $1 \mathrm{KHz}$ and $2 \mathrm{KHz}$ data. These findings suggest that the $1 \mathrm{KHz}$ stimulus and the SL measurement method were more sensitive to inter-subject variation, and therefore have greater potential clinical value.

The Tukey's t-test results quantified inter-group variability at the specific stimulus levels identified by the SME statistic. The similarity between groups A and B suggested by graphical and slope index analyses was confirmed: Tukey's $t$ values in the group A - group B comparison never reached statistical significance. In contrast statistical significance was revealed in the group $\mathrm{C}-$ group $\mathrm{A}$, and group C - group B comparisons, but only at specific stimulus levels.

These statistical results suggest that the label of a 'faster than normal ARA growth rate' in group $C$, is only valid at specific stimulus levels. The discussion that follows however, is based on overall trends of inter-group comparisons, since the implications arising from statistical analyses on a small subject sample may be misleading.

The finding of a faster than normal ARA growth rate in the heterogeneous pathology group (C) agrees with the research of Clemis and Sarno (1980) who found this to be characteristic of cochlear disordered subiects, but is contrary to the findings of Petersen and Liden (1972) and Beedle and Harford (1973) who found a slower growth rate in cochlear disordered subjects. The similarity in growth rate between groups A and B was unexpected since Clemis and Sarno (1980) repeatedly observed a faster than normal ARA growth rate in Meniere's Disease subjects, as did Sprague et al. (1981) in a single case of Meniere's Disease.

The dissimilarity in ARA growth rate between groups $B$ and $C$ was surprising in view of their common lineage - both groups belonged to the cochlear population. This dissimilarity raises two issues for 'discussion: firstly, the variability in ARA data within the cochlear population requires an explanation, and secondly, the interpretation or meaning of a faster than normal ARA growth rate must be questioned. Clearly, a faster than normal ARA growth rate cannot be interpreted as being indicative of cochlear pathology since subjects in the population have also yielded a slower than normal ARA growth rate (Petersen and Liden, 1972) and a normal growth rate as shown in this study.
The term 'recruitment' has been used by Uliel (1980) and Clemis and Sarno (1980) in association with a faster than normal ARA growth rate. The use of this term in this context does not agree with other research. Beedle and Harford (1973) specifically investigated cochlear subjects with concomitant loudness recruitment and found a slower ARA growth rate. Furthermore, in this study all experimental subjects demonstrated loudness recruitment on the Metz. Test, however only those subjects in group $\mathrm{C}$ yielded the faster ARA growth rate.

An alternative interpretation of intra-cochlear variability and a faster ARA growth rate, is based on the relationship between cochlear pathology and the neurological basis of the ARA response system. Evans (1982) states that damage to a cochlear fibre causes a broadening of its frequency threshold curve and a consequent increase in the rate at which adjacent cochlear fibres become activated as a function of increasing stimulus intensity. If this is an acceptable explanation of a faster ARA growth rate, then it is implied that cochlear fibre functioning in the Meniere's Disease group was normal, since this group yielded an ARA growth rate mapping that of normal subjects. No definitive statements can be made regarding the differential effect of cochlear pathology on hair cell morphology in groups $B$ and $C$, however, the variability in state and stage of disease that is characteristic of Meniere's disease patients (Brackman, Selters and Don, 1982) may be of significance when contrasted with the profile of subjects in group $\mathrm{C}$, all of whom reported a minimum 10 year history of bilateral hearing loss with no fluctuating symptomatology. It would be of interest in future research to specifically compare a group of subjects with known hair cell damage, with a group of 'early' stage Meniere's Disease patients who had shown symptom-reversability on Glycerol testing (thus suggesting no permanent hair cell damage).

Audiogram configuration is another variable which may have contributed to the dissimilarity between groups B and C. Five of the six Meniere's subjects showed predominantly low frequency hearing loss whereas this was not characteristic of subjects in group C. Future research may reveal that lower test frequencies (below $1 \mathrm{KHz}$ ) are more sensitive to Meniere's Disease and therefore elicit a faster ARA growth rate in these subjects.

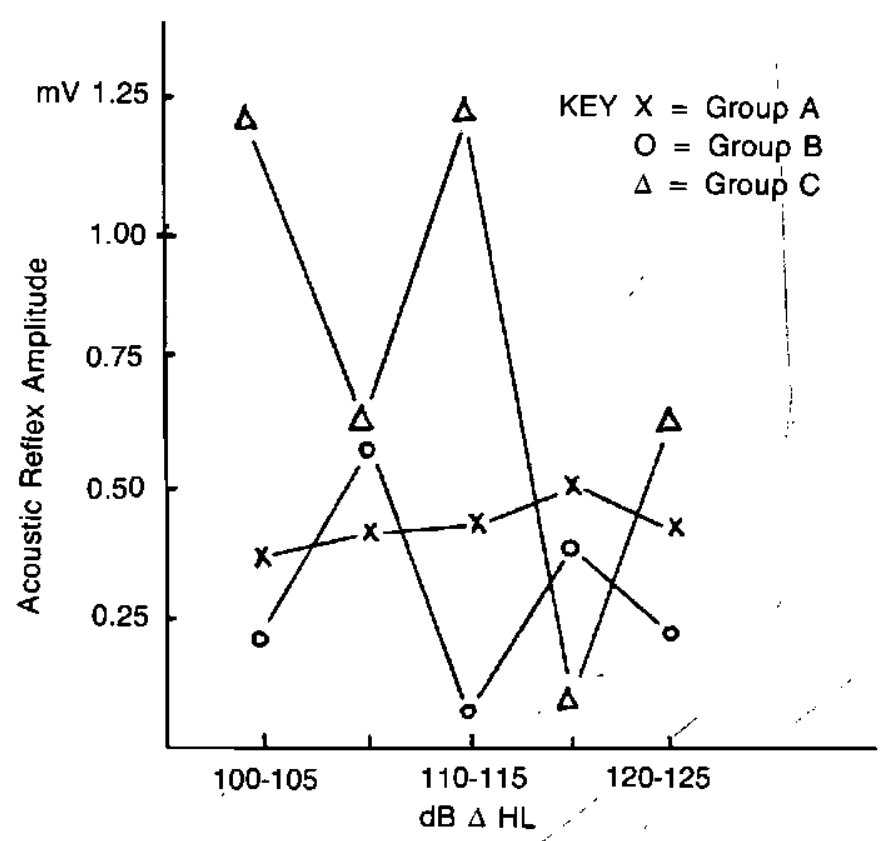

Figure 6 ARA functions for $\Delta \mathrm{HL}$ data at $1 \mathrm{KHz}$, illustrating the ascending-descending configuration similarity hetween groups $B$ and $C$, relative to group A 
These explanations put forward to account for intra-cochlear variability are tentative owing to the use of small sample sizes, and particularly in view of the degree of normal variability in ARA data in this study.

Graphical analyses of $\Delta \mathrm{HL}$ and $\Delta \mathrm{SL}$ data suggested that groups $\mathrm{B}$ and $\mathrm{C}$ behaved similarly, in contrast with the trend revealed by HL and SL data (refer figure 6). This similarity manifested itself in an ascending-descending configuration which was not characteristic of group A. The meaning of this configuration is not certain, however the implication is that $\Delta \mathrm{HL}$ and $\Delta \mathrm{SL}$ measurement methods were more successful than all other methods in distinguishing between normal and cochlear subjects per se. In view of this implication, it is possible that the intra-cochlear variability in this study was a deceptive consequence of measurement method and not a real phenomenon. This does not alter the intra-cochlear variability found within Uliel's (1980) study and between other studies (Clemis and Sarno, 1980; Petersen and Liden, 1972; Beedle and Harford, 1973), which remains worthy of note and is as yet not successfully accounted for.

\section{CONCLUSIONS}

The configuration of ARA growth functions obtained for normal hearing subjects were shown to be influenced by the method of ARA measurement, namely HL versus SL measurement. This variable determined which area of dynamic range of amplitude growth was analysed, and consequently determined the asymptotic versus nonasymptotic configuration difference. The same variable may also account for discrepancies in ARA configuration description in the literature. If this hypothesis is correct then the implication is that a standardised methodological basis for ARA is required, because without reliable normative data the relative influence of hearing impairment cannot be successfully determined.

On the basis of HL and SL measurement methods, the Meniere's Disease group yielded an ARA growth rate similar to that of normal subjects, while the heterogeneous pathology group showed a faster than normal ARA growth rate. This intra-cochlear variability has also been found in other studies and suggests that ARA measurement has a poor prognosis for clinical sensitivity. This is implied since faster than normal ARA growth rate (positive result) might indicate cochlear disorder but a negative test result would not contraindicate cochlear disorder.
$\Delta \mathrm{HL}$ and $\Delta \mathrm{SL}$ measurement methods distinguished, to a certain extent, between the normal and cochlear disordered subjects per $s e$, and therefore offer a better prognosis for test sensitivity than either the HL or SL methods. It could be the purpose of future research, therefore, to examine and compare these and other alternative measurement methods with the aim of improving clinical sensitivity to the degree that would be necessary if ARA measurement was to be included in the impedance audiometry test battery.

\section{REFERENCES}

Beedle, R.K., and Harford, E.R. Comparison of the acoustic reflex and loudness growth in normal and pathological ears. J. Speech Hear. Res., 16, 271-281, 1973.

Borg, E. Dynamic characteristics of the intra-aural muscle reflex. In Acoustic Impedance and Admittance - the measurement of middle ear function. Feldman, A., Wilber, L. (Eds.). The Williams \& Wilkins Co., Baltimore, U.S.A., 1976.

Brackman, D.E., Selter, W.A., and Don, M. Auditory evoked responses. In Otolaryngology 1: Otology, Gibb, A.G. \& Smith, H. (Eds.) Butterworth \& Co., London, 1982.

Clemis, M.D., and Sarno, C.N. The acoustic reflex latency test: clinical application. Laryngoscope, 90, 601-610, 1980.

Dallos, P. Dynamics of the acoustic reflex: phenomenological aspects. J. Acous. Soc. Am., 36, 2175, 1964.

Evans, E.F. Recent advances in cochlear physiology. In Otolaryngology 1; Otology, Gibb, A.G., \& Smith, M. (Eds.) Butterworth \& Co., London, 1982.

Jerger, J. Handbook of Clinical Impedance, Chap. 7. American Electro Medics Corp., New York, 1975.

Jerger, J., and Hayes, D. Latency of the acoustic reflex in eighth nerve tumour. Arch. Otolaryngol., 109, 1-5, 1983.

Osterhammel, P., and Osterhammel, D. Age and sex variations for the normal stapedial reflex thesholds and tympanometric compliance values. Scand. Audio., 8, 153-158, 1979.

Petersen, J. and Liden, G. Some static characteristics of the stapedial muscle reflex. Audiology, 11, 97, 1972.

Sprague, B.H., Wiley, T.L., and Block., M.G. Dynamics of acoustic reflex growth. Audiology, 20, 15-40, 1981.

Uliel, S. Acoustic reflex measurements and the loudness function in sensori-neural hearing loss. S.A.J. Commun. Dis., 27, 58-77, 1980.

Wilson, R.H. and McBride, L.M. Threshold and growth of the acoustic reflex. J. Acous. Soc. Am., 63, 147-154, 1978. 
In close

cooperation

with the

Electro-Acoustic

Department

of Siemens,

one of the world's

leading electrical

and electronic

engineering

companies,

187 Jan Smuts Avenue Lower Rosebank

(Opposite Thrupps)

Tel.: 442-8691 offers hearing aids

and school teaching

equipment

of the highest

quality. 